\title{
БИЛИНГВАЛЬНОЕ ОБУЧЕНИЕ КАК УСЛОВИЕ ИНТЕГРАЦИИ В ГЛОБАЛЬНОЕ ОБРАЗОВАТЕЛЬНОЕ ПРОСТРАНСТВО
}

Актуальность данной статьи обусловлена необходимостью определить роль билингвального обучения в условиях глобализачии образования.

Статья направлена на анализ глобального образования в динамике его развития и выявление возиожностей обучения на двуязычной основе в прочессе формирования конкурентоспособности будуиих выпускников высшего учебного заведения. Цель статьи - раскрыть суиностные характеристики билингвального обучения как формы отражения интеграчионных прочессов в мировой культуре и образовании, а также актуализировать дидактико-методические основы построения билингвальных программ (куррикулумов) как способа формирования коммуникативной компетенции и конкурентоспособности профессионала в образовательной парадигме современного вуза.

Ключевые слова: глобальное образование, билингвальное обучение, конкурентоспособность, коммуникативная компетенция, академическая мобильность, билингвальный куррикулум.

\section{Tatiana Danilova \\ BILINGUAL TRAINING AS A CONDITION FOR INTEGRATING INTO GLOBAL EDUCATION}

The relevance of this article is determined by the need to identify the role of bilingual training in the context of the globalization of education.

The article is aimed at the analysis of global education in its development dynamics and identifying the opportunities of bilingual training in the process of forming the competitiveness of future graduates of a higher educational institution. The purpose of the article is to reveal the essential characteristics of bilingual training as a form of reflection of integration processes in the world culture and education as well as to update the didactic and methodological foundations of the creation of bilingual programs (curriculums) as a means of forming communicative competence and the competitiveness of a professional in the educational paradigm of a modern university.

Key words: global education, bilingual training, competitiveness, communicative competence, academic mobility, bilingual curriculum.

Bведение / Introduction. Размышляя о сущности значимых социально-экономических процессов на рубеже XXI века, академик А. Д. Сахаров отмечал, что именно конвергенция есть единственный путь спасения человечества. Данное утверждение крупного мыслителя дает основание полагать, что современное видение дальнейшего развития национальных образовательных систем должно выходить за рамки привычных представлений о соотношении таких понятий как ((традиция» и (иинновация), ((консерватизм» и «(творчество», «единое» и «общее) .

Речь идет о том, что в глобальном понимании сущности научного познания по настоящему актуальной становится идея о необходимости качественного скачка в образовательной политике больших и малых региональных формирований, а также перехода от «разбросанности» в подходах к познанию объективной реальности к схождению и сближению.

По мнению большинства ученых-исследователей, новым методологическим ключом к пониманию социально-образовательного вектора развития современных образовательных процессов является глобальное образование, выступающее важнейшей фундаментальной ценностью не только европейской, но и мировой культуры в целом [27]. 
Следует отметить, что идея глобального образования, которая начала оформляться еще в начале 60-х годов прошлого столетия, послужила основанием для создания в 1970 году негосударственной организации "The American Forum for Global Education", положившей начало движению за Глобальное образование, как в США, так и на международной арене в целом. По мнению членов Форума, глобальное образование представляет собой не просто совокупность множества национальных образовательных пространств и систем, оно является особой «мегасистемой», в которой задаются и реализуются цели национальной и мировой политики в области образования, а также функционируют специфические связи и отношения между государствами и их образовательными системами, направленные на непрерывное расширение возможностей развития личности.

Не будет преувеличением сказать, что глобальное образование является предметом пристального внимания отечественных и зарубежных ученых, занимающихся разработкой современных образовательных методик и технологий. Так Роберт Хенви в качестве основных измерений глобального образования предложил взять за основу следующее:

- осознание неоднородности восприятия мира;

- осознание экологических угроз

- $\quad$ кросс-культурную грамотность

- знание глобальной динамики;

- $\quad$ рефлексивное и ответственное отношение к собственным поступкам [23].

Иными словами, выдвинутые Р. Хенви постулаты ориентируют человека нового глобального поколения на установление осознанных гармоничных отношений с миром во всех его проявлениях и деятельность по их сохранению, а, именно, на:

- отказ от модерных метанаративов и стремления навязывать единые модели развития;

- знание о состоянии природы, её процессах, изменениях и месте в ней человека;

- непредвзятое отношение к различным культурам и направленность на установление диалога;

- понимание основных происходящих в мире процессов;

- умение принимать обдуманное решение и нести за него ответственность.

В дополнение к положениям Р. Хэнви, озвученным выше, М. Боткин подчёркивает, что особую значимость в процессе подобного общения с миром приобретает сознательное предвосхищение, т.е. требование предвиденья и прогнозирования событий и их последствий при принятии ответственных решений каждым человеком, а также личная сопричастность (направленность на активное сотрудничество, диалог и взаимодействие).

Таким образом, приоритетной задачей глобального образования является формирование взгляда на мир как на единое целое, где благополучие каждого зависит от благополучия остальных. Следовательно, целью подобного образования становится преодоление таких значимых современных проблем как разделение мира на враждующие социумы; разлада человека с природным окружением; раздельности понятий разума и души в самом человеке [8].

Глобализация образования на этапе подготовки будущего профессионала предполагает необходимость обучения в различных странах, расширяя потенциальный выбор набора дисциплин и обеспечивающих их научно-педагогических кадров. В данных условиях особую актуальность приобретает разработка валидной сопоставимой системы зачетов и кредитов, создающей основу для накопления освоенных курсов и признания результатов их изучения различными международными учебными заведениями [2]. Многочисленные программы академической мобильности (Erasmus + , Eranet, Marie Curie, Fulbright, Youth, Citizenship, Gruntdvig, DAAD и др.) предоставляют студентам и профессорско-преподавательскому составу огромные возможности для обучения, стажировки и обмена опытом в зарубежных вузах. Наряду с академическим ростом, участие в подобных программах во многом обеспечивает личностное развитие будущих профессионалов, 
так как формирует в них умение выбирать пути взаимодействия с окружающим миром, развивает способность мыслить в сравнительном аспекте и изменять самовосприятие, обогащая свой лингвосоциокультурный опыт, а также совершенствуя общие и профессиональные компетенции, что позволяет им стать по-настоящему конкурентоспособными на мировом рынке труда [22].

Иными словами, глобализация образования во многом способствует не только укреплению индивидуальных позиций будущего профессионала и предоставляет возможности для его всестороннего развития, расширяя при этом выбор условий и места приложения его творческих сил, но также позволяет концентрировать человеческий капитал высокого качества и стимулировать конкуренцию между странами в борьбе за носителей интеллектуальных ресурсов.

Maтериалы и методы/Materials and methods. В русле рассматриваемой проблемы следует отметить, что в академической парадигме современного отечественного вуза глобализация образования ведет к усилению роли билингвального обучения. Это объясняется, прежде всего, тем, что двуязычная подготовка призвана обеспечивать прочную технологическую и методическую базу для интернационализации и унификации знаний в контексте перехода на двухуровневую систему подготовки будущего профессионала - бакалавриат и магистратуру. Являясь неотъемлемой частью поликультурного образования, билингвальное обучение способствует повышению мотивации студентов (особенно, нелингвистических специальностей) к изучению иностранного языка, который предоставляет уникальную возможность воспользоваться преимуществами открытого общества, а также является залогом их конкурентоспособности, позволяя успешно реализовывать свой личностный и профессиональный потенциал в иноязычной среде.

Отметим, что под билингвальным обучением понимается специфичная организация учебного процесса, при которой становится возможным использование более чем одного языка в качестве языка преподавания. Причем второй язык в подобном случае является не только объьектом изучения, но одновременно выступает средством общения и языком преподавания. [17, с. 63]

Согласно современному подходу базовыми составляющими обучения на билингвальной основе являются:

1) обучение предмету и овладение студентами предметным знанием в определенной области на основе взаимосвязанного использования двух языков (родного и неродного) в качестве средства образовательной деятельности;

2) обучение иностранному языку в процессе получения определенного предметного знания за счет одновременного использования двух языков;

3) овладение иностранным языком как средством образовательной деятельности.

Следует отметить, что в условиях билингвального обучения в вузе у студентов (особенно нелингвистических специальностей) возникает особая мотивация к овладению иностранным языком. Ее специфика заключается в том, что к познавательной мотивации (т. е. желанию освоить другую языковую картину мира и расширить свои фоновые знания) присоединяется профессиональная, заставляющая по-настоящему переосмыслить и осознать значимость иностранного языка для будущей карьеры. Иными словами, билингвальное обучение создает предпосылки для развития специфического компонента мотивации овладения иностранным языком - так называемой билингвальной мотивации, в основе которой лежит потребность в самоактуализации. Структурными элементами билингвальной мотивации выступают мотивы применения иностранного языка, творческие и коммуникативные мотивы [18, с. 35].

Отдельные ученые, в числе которых И. А. Зимняя и М. В. Матюхина, считают, что при специфично выстроенной системе обучения образуется тесная взаимосвязь между мотивацией цели и мотивацией достижения. С этим трудно не согласится, ведь цель - именно то звено, через которое можно управлять процессом формирования мотивации. Особенность билингвального обучения, при котором профессиональные знания приобретаются через иноязычный информационный канал, заключается в том, что в его условиях у студента усиливается потребность в достижении цели, в результате чего познавательная мотивация преобразуется в билингвальную [6, с. 13]. 
Важен и тот факт, что при двуязычном обучении, реализуемом в условиях образовательного процесса вуза, билингвальная мотивация развивается при наличии в мотивационной сфере студентов нелингвистических специальностей реально действующих познавательных мотивов, которые со временем трансформируются в профессиональные. Кроме того, наблюдаются также существенные отличия в структуре мотивации студентов-нелингвистов с различным уровнем иноязычной коммуникативной компетенции. Так, у учащихся с высоким уровнем данной компетенции преобладают билингвальные мотивы овладения иностранным языком, у студентов со средним уровнем преобладающими являются познавательные мотивы, а с низким уровнем - утилитарные. Однако, несмотря на разноуровневость языковой компетенции, двуязычная подготовка обеспечивает очевидный качественный прирост на ценностно-мотивационном уровне личности обучаемых, во многом обусловливая повышение мотивации достижения, которая выступает гарантом их академических и профессиональных успехов в будущем.

Еще одним несомненным преимуществом двуязычного обучения в процессе подготовки конкурентоспособных кадров в академическом пространстве вуза является то, что в его условиях происходит быстрое и эффективное формирование коммуникативной компетенции будущих выпускников. Под коммуникативной компетенцией понимается особое качество речевой личности, приобретенное в процессе естественной коммуникации или специально организованного обучения (в данном случае билингвального). Эта компетенция является комплексной и складывается из нескольких составляющих, в числе которых языковая, предметная, прагматическая и лингвистическая компетенции. Языковая компетенция подразумевает знание единиц языка и связи, т.е. правила их соединения. Обладая двусторонним характером, данная компетенция объединяет язык и речь и характеризует личность как человека, владеющего языком, и его умение пользоваться языком на основе грамматических правил. Предметная компетенция формируется на основе активного владения общей лексикой, т.к. язык отражает в словах предметы окружающего мира и отношение между ними, формируя в сознании говорящего картину мира. Что касается прагматической компетенции, то она предполагает отбор лицом, порождающим устную или письменную речь, языкового материала (нужных форм, типа речи) и его умение пользоваться вариативными формами с учетом условий речевого акта, статуса адресата, объекта обсуждения и функционально-стилевых разновидностей. И, наконец, лингвистическая компетенция имеет характер знаний, относящихся к лингвистике, как к науке, и реализуется у лиц, специально занимающихся языковедением.

Анализируя билингвальное обучение в контексте подготовки конкурентоспособного профессионала в условиях глобализации образования, отметим, что его роль в данном случае трудно переоценить, т. к. оно призвано обеспечить синтез культурно-специфических когнитивных стилей, а также социальных моделей поведения и коммуникационных кодов с целью создания у обучаемых единства формально-абстрактного, независимого от окружения мышления с сохранением при этом их уникальной идентичности. Иными словами, обучение на двуязычной основе обеспечивает не только профессиональное, но и глубокое личностное развитие на когнитивном, ценностно-мотивационном и деятельностно-поведенческом уровнях.

Так, в процессе билингвального обучения на когнитивном уровне происходит освоение будущими профессионалами образцов и ценностей мировой культуры, культурно-исторического и социального опыта различных стран и народов.

На ценностно-мотивационном уровне осуществляется формирование социально-установочных и ценностно-ориентационных предрасположенностей обучающихся к межкультурной коммуникации и обмену, а также развитие толерантности по отношению к другим странам, народам, культурам и социальным группам.

И, наконец, на деятельностно-поведенческом уровне происходит активное социальное взаимодействие с представителями различных культур при сохранении собственной культурной идентичности. 
Следует отметить, что в образовательной парадигме современного вуза залогом качественной подготовки конкурентоспособного профессионала на двуязычной основе является грамотно смоделированный билингвальный куррикулум, т.е. образовательная программа, которая призвана решать не только целый комплекс воспитательно-образовательных задач, но также обеспечивающая приобщение обучаемых к ценностям, как мировой, так и отечественной культуры $[9$, с. 30].

Очевидно, что, являясь по своей сути разновидностью образовательной программы, билингвальный куррикулум обладает ее основными характеристиками, а именно:

1) комплексностью и целостностью всех компонентов учебной программы;

2) наличием таксономии реальных и достижимых целей разного уровня;

3) адекватностью форм методов и средств целям и содержанию;

4) высокой степенью открытости.

Необходимо подчеркнуть, что, отвечая в полной мере сущностным характеристикам традиционных образовательных программ, билингвальный куррикулум, обладает рядом своих особенностей, к которым можно отнести:

1) его поликультурную направленность;

2) многообразие целей, ориентированных на преодоление рамок предметной монокультуры;

3) высокий уровень межпредметной интеграции;

4) сочетание событийно-экземплярного, компаративистского и интегративного подходов при конструировании содержания программы;

5) учет индивидуально-личностной траектории развития студентов и их мотивационной готовности к освоению билингвальной программы;

6) профессиональное взаимодействие преподавателей, совместно разрабатывающих и реализующих программу;

7) использование технологий открытого обучения.

Иными словами, обучение по билингвальным куррикулумам в условиях вуза позволяет будущим профессионалам приобрести должный уровень поликультурной образованности, имеет высокий для них ценностный смысл, обеспечивает качественное формирование их общих и профессиональных компетенций, и, следовательно, обеспечивает качественные преобразования на когнитивном, ценностно-мотивационном и деятельностно-поведенческом уровнях. Все это выступает прочной основой для формирования их конкурентоспособности, которая, являясь одной из целей двуязычной подготовки, представляет собой сложное, динамичное личностное образование, включающее комплекс внутренних инструментально-интеграционных мотивов, направленных на высокое качество профессиональной деятельности, в том числе в иноязычной среде; знаний по специальности и в области иностранного языка, высокий уровень коммуникативной компетенции, а также, важных личностных качеств, обусловливающих успешность межкультурной интеракции.

Pезультаты и обсуждение/ Results and discussion. В последнее время все больше отечественных вузов моделируют свой образовательный процесс с использованием билингвальных куррикулумов. В их числе и Северо-Кавказский федеральный университет (далее СКФУ), в котором уже на протяжении ряда лет по отдельным специальностям и направлениям успешно реализуется билингвальное обучение, позволяя осуществлять подготовку конкурентоспособных профессионалов, способных эффективно решать задачи как внутри страны, так и за ее пределами, быстро и грамотно реагировать на меняющиеся производственные ситуации с учетом социокультурных и поведенческих специфик представителей делового сообщества, т. е. обеспечивать одинаково высокое качество профессиональной деятельности в родной и в иноязычной среде.

Следует подчеркнуть, что в СКФУ наиболее богатый практический опыт в области подготовки профессиональных кадров по билингвальным куррикулумам накоплен профессорско-преподавательским составом Института Экономики и Управления. При формировании учебных 
планов и рабочих программ, призванных обеспечить эффективное обучение на двуязычной основе студентов-бакалавров таких экономических направлений как «Международный менеджмент» и «Мировая экономика», достаточно большой удельный вес с точки зрения зачетных единиц имеет дисциплина «Иностранный язык (английский)», изучение которой рассчитано на четыре семестра. Большой объем академических часов, отведенных в билингвальном куррикулуме на данную дисциплину, обусловлен, во-первых, тем, что освоение иностранного языка является главным условием обучения на двуязычной основе, а также тем, что это происходит в условиях искусственного билингвизма, что предполагает дополнительные усилия для эффективного формирования коммуникативной компетенции обучаемых.

Как отмечалось ранее, одной из целей билингвального обучения в условиях глобального образования является подготовка конкурентоспособного профессионала, которого отличает высокое развитие личности на когнитивном, ценностно-мотивационном и деятельностно-поведенческом уровнях. Чтобы обеспечить позитивную динамику на данных уровнях, рабочая программа по дисциплине «Иностранный язык» для студентов-экономистов, обучающихся на двуязычной основе, обогащена лингвистическими и социокультурными блоками, которые вводятся дополнительно к рекомендованному учебнику в каждом из последующих семестров.

Так, в первом семестре иноязычную профессионально-ориентированную лексику студенты-билингвалы осваивают по базовому учебнику экономической направленности, а грамматические умения и навыки совершенствуют на занятиях по дисциплине «Корректирующий курс по иностранному языку», где в качестве учебного-методического материала используется авторское пособие «Английская грамматика для студентов университета», разработанное по блочно-модульному принципу и включающее лингвистические явления, необходимые для корректного построения речевого высказывания на иностранном языке. Такой подход не только стимулирует развитие грамматических умений и навыков студентов, но также способствует осознанию ими значимости иностранного языка для своей профессиональной деятельности, обеспечивая качественные преобразования на ценностно-мотивационном и когнитивном уровнях.

Во втором семестре совершенствование вербально-коммуникативных умений и навыков, призванных обеспечить высокое качество будущей профессиональной деятельности в иноязычной среде, происходит как на практических занятиях по основному иностранному языку, так и в рамках мини-курса «Topical Economic Issues». Усвоение изучаемого материала происходит в форме интерактивной дискуссии и включает подготовку и обсуждение текущих экономических событий, а также презентацию рефератов и докладов по профессиональной тематике. Увеличение объема речевой деятельности на иностранном языке на данном этапе дает позитивный прирост не только на ценностно-мотивационном и когнитивном уровнях личности обучаемых, но также обеспечивает очевидную динамику на деятельностно-поведенческом.

Одним из важных элементов билингвального куррикулума является использование в третьем семестре на практических занятиях по иностранному языку авторского учебного пособия «The Basics of Strategic Management», разработанного с использованием аутентичных английских источников и включающего следующие темы: 1) Defining Strategic Management, 2) Key Terms to Strategic Management, 3) The Strategic-Management Model, 4) Benefits of Strategic Management, 5) Factors Important in Strategic Decisions Making. Каждая тема оформлена в отдельный модуль, состоящий из таких разделов как: Reading Skills, Word Power, Grammar Focus, Communication Workshop. B конце семестра студенты закрепляют полученные знания и совершенствуют умения и навыки, принимая участие в видео-семинаре на тему «Strategic Management in Action». В качестве материала для семинара используется видеоролик о компании "Nuga Medical Co., Ltd." на английском языке. Упражнения учебного пособия, градуированные по уровню сложности, а также практические интерактивные задания, выполняемые на семинаре, позволяют студентам обо- 
гащать свои иноязычные и профессиональные знания, а также совершенствовать вербально-коммуникативные умения и навыки, что обеспечивает положительный рост личности обучаемых на ценностно-мотивационном, когнитивном и деятельностно-поведенческом уровнях.

На заключительном этапе изучения дисциплины «Иностранный язык» (четвертый семестр) в качестве дополнения к основному учебнику, в рамках которого продолжается освоение профессионально-ориентированной лексики, студенты-билингвалы изучают мини-курс на английском языке «The Competitive Professional», состоящий из трех основных блоков по следующей тематике: «The Basics of Inter-Cultural Communication», «Body Language», «Successful Presentation». Содержание курса призвано актуализировать и обогатить социокультурные знания будущих профессионалов, а также научить их психологическим нюансам публичной речи.

Непрерывный мониторинг академической успеваемости студентов экономических направлений, обучающихся по билингвальному куррикулуму, свидетельствует о том, что уже к третьему семестру они достигают уровня коммуникативной компетенции, достаточного не только для успешного освоения специальных дисциплин на иностранном языке, но также позволяющего участвовать в вебинарах по профессиональной тематике, проводимых зарубежными коллегами, прослушивать лекции приглашенных профессоров (Visiting Professor) и участвовать в программах академической мобильности, инициируемых как вузами-партнерами СКФУ (la Sapienza, Рим, Италия; университет Лиссабона, Португалия; университет Чанджоу, Китай и др.), так и различными зарубежными фондами.

На современном этапе развития общества, как в отечественной, так и в зарубежной науке изучение проблемы билингвального обучения приобретает всё большую актуальность в связи с необходимостью пересмотра образовательных потребностей мирового социума и эффективных способов их удовлетворения. В условиях глобализации стремительно расширяется межкультурное взаимодействие и формируется единое научно-экономическое пространство, что обусловливает потребность в аккумуляции и практическом применении мирового передового опыта в области подготовки профессиональных кадров на двуязычной основе.

Обладая многоаспектностью, вопросы билигвального обучения являются предметом пристального внимания ученых всего мира. В частности, разработкой концептуальных основ моделей билингвального образования в современной зарубежной школе занимались такие исследователи как R. Baur, K. Wenderot, K. R. Bausch, W. Butzkamm, I. Christ, C. Baker, T. Skutnab-Kangas и др. [28, c. 20] Среди российских ученых данная проблематика нашла свое отражение в работах Е. И. Бражник, Л. И. Плиевой, Н. Е. Сорочкиной и т.д. Исследования С. В. Бобровой, И. В. Галковской, Т. В. Светенко, Л. В. Смирновой и пр. посвящены анализу зарубежного опыта двуязычного обучения и возможности его адаптации в России с учетом социокультурных условий.

Следует подчеркнуть, что большинство исследований в данной области посвящено билингвальному обучению на этапе начальной и средней школы. Однако в условиях глобализации налицо усиление тенденции к реализации двуязычного образования на третичном уровне, т. е. в академической парадигме современного вуза. В России теоретические основы конструирования билингвальных образовательных программ (куррикулумов) в высшей школе как средства поликультурного воспитания студентов и повышения их мотивации к изучению иностранного языка были в основном разработаны такими российскими учеными как И. В. Алексашенкова, Т. Д. Крысанова, Т. Н. Кучерова, М. Н. Певзнер, А. И. Шаповалов и С. В. Шубин, в то время как за рубежом подобные вопросы отражены в работах L. Huber, J. Wildt и др. [1, с. 8].

Что касается конкурентоспособности, то обращение ученых разных научных областей к данному понятию обусловлено стремлением обозначить социальную активность личности во всех сферах ее жизнедеятельности. Необходимо отметить тот факт, что отдельные аспекты конкурентоспособности являются предметом интереса зарубежных исследователей, в числе которых И. Ансофф, Ф Вудкок, Т, Санталайнен, Ф. Хесселбейн, М. Голдсмит, А. Сомервил и др. 
Не меньшее внимание уделяют разработке понятия «конкурентоспособность» и отечественные ученые. В частности, Р. А. Фатхутдинов, Д. В. Чернилевский, С. Н. Широбоков посвятили свои работы изучению конкурентоспособности как показателя качества подготовки профессионалов $[13$, с. 20]. В исследованиях Л. М. Митиной представлен психологический аспект развития конкурентоспособной личности [10, с. 12]. Титова О. А. делает упор на формирование конкурентоспособной личности в условиях современного образования [12, с. 57]. В работах Р. Я. Ахметшина, Н. В. Борисовой, С. А. Борисенко, О. И. Полькиной, Н. В. Фомина разработаны базовые и обобщенные модели личности и деятельности конкурентоспособного специалиста в разных областях профессиональной деятельности.

Однако, несмотря на обширную теоретическую базу в области подготовки квалифицированных кадров на двуязычной основе и неослабевающий интерес ученых к понятию «конкурентоспособность», проблемы, связанные с влиянием билингвального обучения на формирование конкурентоспособности будущего профессионала, до настоящего времени оставались неразработанными. Это обстоятельство определило научную новизну данной работы, которая заключается в установлении роли двуязычной подготовки в процессе формировании конкурентоспособности будущего выпускника в условиях академической парадигмы современного отечественного вуза.

Заключение / Conclusion. Современное общество вступило в совершенно новую ступень своего развития, когда ведущей тенденцией признается глобализация социально-экономических и культурных процессов в мире. В контексте образования процессы глобализации проявляются в конвергенции, основной характеристикой которой является сближение идей, институциональных моделей и практики работы вузов. В создавшихся условиях на первый план выходят идеи интернационализации образования, направленные на сближение национальных систем, а также нахождение и развитие в них общих универсальных концептов и компонентов, т.е. тех общих оснований, которые составляют основу разнообразия национальных культур, способствуя их взаимообогащению. Одними из основных инструментов интернационализации выступают академический обмен студентами, преподавателями и исследователями, признание дипломов и ученых степеней, общие стандарты образования и др.

Стремление к открытому обществу и интеграции в глобальное научно-экономическое пространство диктует повышенные требования, предъявляемые к современным выпускникам вуза, в связи с чем возникает необходимость пересмотра существующего содержания отечественного высшего образования в сторону усиления его практической, личностной и поликультурной ориентированности. Подобные реалии обусловливают социальную потребность в подготовке профессионала нового формата, обладающего не только высокоразвитыми компетенциями, но также конкурентоспособного на мировом рынке. В связи с этим, всё более значимую роль в образовательной парадигме современного вуза играет обучение на двуязычной основе, призванное обеспечивать будущим выпускникам не только широкий доступ к информации в различных предметных областях в соответствии с их индивидуальными потребностями, но также расширять возможности непрерывного образования, давая им дополнительные шансы успешно реализовывать свой профессиональный и личностный потенциал в иноязычной среде.

В условиях вуза билингвальная подготовка представляет собой взаимосвязанную деятельность преподавателя и студентов в процессе изучения отдельных специальных предметов или предметных областей средствами родного и иностранного языков, в результате которой достигается синтез определенных компетенций, обеспечивающий высокий уровень владения иностранным языком и глубокое освоение содержания профессиональной дисциплины. Особенность обучения на двуязычной основе в высшей школе проявляется, прежде всего, в том, что, получение профессиональных знаний через иноязычный информационный канал усиливает потребность студентов (особенно нелингвистических специальностей) в достижении цели, в результате чего их познавательная мотивация преобразуется в билингвальную. 
Наряду с этим, даже в условиях искусственного билингвизма обучение на двуязычной основе способствует более эффективному формированию коммуникативной компетенции будущих профессионалов, призванной обеспечивать успешность интеракции на иностранном языке.

Значимая роль билингвального обучения в формировании конкурентоспособного профессионала в образовательной парадигме современного отечественного вуза проявляется также в том, что оно обеспечивает глубокое личностное развитие студентов на когнитивном, ценностно-мотивационном и деятельностно-поведенческом уровнях. Это объясняется тем, что в процессе подготовки на двуязычной основе происходит синтез социальных моделей поведения, коммуникационных кодов и культурно-специфических когнитивных стилей обучаемых, в результате чего образуется единство формально-абстрактного, независимого от окружения мышления с сохранением при этом уникальной идентичности личности.

Успешность формирования конкурентоспособности будущего профессионала в условиях двуязычной подготовки во многом зависит от содержания и моделирования билингвального куррикулума, представляющего из себя образовательную программу, которая, наряду с решением комплекса воспитательно-образовательных задач, обеспечивает приобщение обучаемых к ценностям мировой и отечественной культуры. Обладая всеми характеристиками традиционных образовательных программ, билингвальный куррикулум имеет свои отличительные особенности, среди которых его поликультурная направленность, высокий уровень межпредметной интеграции, многообразие целей, ориентированных на преодоление рамок предметной монокультуры и др.

Содержание билингвального куррикулума, нацеленного на формирование конкурентоспособности квалифицированных кадров, строится с учетом событийно-экземплярного, компаративистского и интегративного подходов, а также индивидуально-личностной траектории развития студентов и их мотивационной готовности к освоению программы на двуязычной основе. Успешность данного процесса во многом обусловлена как профессиональным взаимодействием профессорско-преподавательского состава, совместно разрабатывающего и реализующего куррикулум, так и использованием технологий открытого обучения.

Глобализация образования и потребность современного общества в конкурентоспособном профессионале особенного формата объясняет все более активный переход отечественных вузов на двуязычные программы обучения. Практическое внедрение билингвального куррикулума в процесс подготовки квалифицированных кадров обеспечивает будущим выпускникам не только широкий доступ к информации в различных предметных областях и получение новой информации в соответствии с их индивидуальными потребностями, но также расширяет возможности непрерывного образования, способствует совершенствованию их коммуникативной компетенции в специальных предметных целях, качественному улучшению профессиональной подготовки, развитию навыков межкультурного взаимодействия, а также повышению мотивации при изучении иностранного языка, роль которого в данном случае трудно переоценить.

Значимость иностранного языка, главная функция которого в процессе двуязычной подготовки заключается в приобщении к миру специальных знаний, во многом объясняет большой удельный вес данной учебной дисциплины при моделировании билингвального куррикулума. Накопленный практический опыт свидетельствует о том, что в условиях обучения на двуязычной основе, обогащение рабочей программы по иностранному языку дополнительными лингвистическими и социокультурными блоками позволяет обеспечить быструю позитивную динамику и качественные преобразования на когнитивном, ценностно-мотивационном и деятельностно-поведенческом уровнях личности будущих профессионалов, что способствует эффективному формированию их конкурентоспособности в образовательной парадигме современного вуза. 


\section{ЛИТЕРАТУРА И ИНТЕРНЕТ-РЕСУРСЫ}

1. Алексашенкова, И. В. Билингвальная образовательная программа (куррикулум) как средство поликультурного образования студентов. Текст: диссертация на соискание ученой степени кандидата педагогических наук: 13.00.01 / Ирина Валентиновна Алексашенкова. - Великий Новгород, 2000. 148 с.

2. Бражник, Е.И. Интеграционные процессы в современном европейском образовании: Монография / Е.И. Бражник; Рос. гос. пед. ун-т им. А.И. Герцена. - СПб.: БАН, 2001. - 200 с.; 20 см.; ISBN 5-33600012-4

3. Вербицкий, А. А. Компетентностный подход и теория контекстного обучения /Материалы к четвертому заседанию методологического семинара 16 ноября 2004 г. http://www.rc.edu.ru/rc/bologna/ seminar.php

4. Данилова Т. А. Билингвальное обучение в образовательной парадигме современного вуза // Формирование языковой компетенции в условиях поликультурного общества: сборник научных работ заочной Международной научно-практической конференции (28-29 апреля 2014 г.). Ставрополь: Изд-во СКФУ, 2014. С. 66-72.

5. Данилова Т. А. Возможности билингвальной подготовки в формировании конкурентоспособности будущего профессионала // Актуальные вопросы развития языковой личности в условиях современного поликультурного общества (коллективная монография) / под ред. Шибковой О. С. Ставрополь: Изд-во СКФУ, 2016. С. 30-43.

6. Зимняя И. А. Ключевые компетентности как результативно-целевая основа компетентностного подхода в образовании // Ректор ВУЗа. 2005. № 6. С. 13-29.

7. Изаренков Д. И. Базисные составляющие коммуникативной компетенции и их формирования на продвинутом этапе обучения студентов-нефилологов // Русский язык за рубежом. - 1990. - №4.

8. Марков А. П. Образовательные цели и агенты глобализации // Образование в условиях формирования нового типа культуры: ІІІ международные лихачевские научные чтения. СПб.: СПбГУП, 2003

9. Мельникова М. С. Конструирование междисциплинарных модульных программ в системе билингвального образования. Текст: диссертация на соискание ученой степени кандидата педагогических наук: 13.00.01 / Мельникова Мария Сергеевна; [Место защиты: Новгород. гос. ун-т им. Ярослава Мудрого]. - Великий Новгород, 2008.- 247 с.: ил. РГБ ОД, 61 08-13/599

10. Митина, Л. М. Психология развития конкурентоспособ̆ной личности. М.: МПСИ; Воронеж: Изд-во НПО «МОДЭК», 2002.

11. Савченко И. И., Мылов И. Д. Проблемы развития методологии понятия конкурентоспособности // Международный журнал прикладных и фундаментальных исследований. 2015. № 11-3. С. 435-438; URL: http://applied-research.ru/ru/article/view?id=7756

12. Титова О. А. Формирование конкурентоспособной личности в условиях современного образования // Молодой ученый. 2016. №16.1. С. 57-60. - URL https://moluch.ru/archive/120/33337/

13. Фатхутдинов, Р. А. Конкурентоспособность: экономика, стратегия, управление. М.: ИНФРА-М, 2000.

14. Хабарова Л. П. Билингвальное образование в высшей школе: зарубежный и отечественный опыт // Известия ПГПУ им. В. Г. Белинского. 2011. № 24. С. 846-852.

15. Хесселбейн Ф., Голдсмит М., Сомервилл А. Лидерство без границ. М., 2001. Научная библиотека диссертаций и авторефератов disserCat http://www.dissercat.com/content/konkurentosposobnostlichnosti-v-sovremennom-transformiruyushchemsya-obshchestve-sotsialno-f\#ixzz5M227AG3n

16. Хусаенова А. А. Компетентностный подход в высшем образовании // Образование и воспитание. 2015. №4. C. 23-26. — URL https://moluch.ru/th/4/archive/13/243/

17. Ширин А.Г. Дидактико-методические аспекты процесса билингвального образования// Вестник новгородского государственного университета. 2005. № 31. С. 63-66.

18. Шубин С. В. Мотивация овладения иностранным языком в условиях билингвального обучения в вузе: дисс. ... канд. пед. наук. Великий Новгород: НовГУ имени Ярослава Мудрого, 2000. 148 с.

19. Baker C. Foundations of Bilingual Education and Bilingualism. Clevedon: Multilingual Matters. 2006. 492 pp.

20. Coyle, D., 2010. Evaluating the impact of CLIL programmes, in: Content and Language Integrated Learning. Cambridge English. 
21. Erasmus+/EU programme for education, training, sport and youth. URL http://ec.europa.eu/programmes/ easmus-plus/node_en

22. European commission. Multilingualism. [Электронный ресурс]// Content and Language Integrated Learning (CLIL): сайт. URL: http://ec.europa.eu/education/languages/language-teaching/doc236_en.htm

23. Hanvey, R.G. An Attainable Global Perspective. Theory into Practice. Vol. 21, No. 3, Global Education (Summer, 1982), p.p.162-167.

24. Lasagabaster, D., 2008. Foreign Language Competence in Content and Language Integrated Courses. The Open Applied Linguistics Journal 1, 31-42.

25. Meriso-Storm, T., 2001. Students' first language skills in bilingual education. Journal of Communications Research3, 85-101.

26. Ruiz de Zarobe, Y.R., 2013. CLIL Implementation: from policy makers to individual initiatives. International Journal of Bilingual Education and Bilingualism, 16:3. 231-243.

27. Sakharov A.D. Collected Scientific Works / Ed. D. ter Haar, D.V.Chudnovsky and G.V.Chudnovsky. - New York and Basel: Marcel Dekker Inc., 1982.

28. Skutnabb-Kangas T. Bilingualism or not? The education of minorities. Clevedon, Avon: Multilingual Matters, $1984.378 \mathrm{pp}$.

29. TEL2L. Teaching subjects through the medium of foreign language [Электронный pecypc] // Bilingual Education Programmes in Germany: сайт. URL: http://www.unavarra.es/tel21/eng/germany.htm

30. TEL2L. Teaching subjects through the medium of foreign language [Электронный pecypc] // Models of bilingual education: сайт. URL: http://www.unavarra.es/tel21/eng/Worldcontext.htm

31. TEL2L. Teaching subjects through the medium of foreign language [Электронный pecypc]// The Trilingual Education system in Luxembourg: сайт. URL: http://www.unavarra.es/tel21/eng/luxembourg.htm

\section{REFERENCES AND INTERNET RESOURCES}

1. Aleksashenkova, I. V. Bilingval'naya obrazovatel'naya programma (kurrikulum) kak sredstvo polikulturnogo obrazovaniya studentov (Bilingual educational program (curriculum) as a means of multicultural education for students). Tekst: dissertatsiya na soiskanie uchenoi stepeni kandidata pedagogicheskikh nauk: 13.00.01/ Irina Valentinovna Aleksashenkova. - Velikii Novgorod, 2000. 148 p.

2. Brazhnik, E.I. Integratsionnye protsessy v sovremennom evropeiskom obrazovanii (Integration processes in modern European education): Monografiya / E.I. Brazhnik; Ros. gos. ped. un-t im. A.I. Gertsena. $-\mathbf{S P b}$.: BAN, 2001. - 200 p.; 20 sm.; ISBN 5-336-00012-4

3. Verbitskii, A.A. Kompetentnostnyi podkhod i teoriya kontekstnogo obucheniya (Competence approach and the theory of contextual learning) / Materialy k chetvertomu zasedaniyu metodologicheskogo seminara 16 noyabrya $2004 \mathrm{~g} .$. http://www.rc.edu.ru/rc/bologna/seminar.php

4. Danilova, T. A. Bilingval'noe obuchenie $\mathrm{v}$ obrazovatel'noi paradigme sovremennogo vuza (Bilingual education in the educational paradigm of a modern university). // Formirovanie yazykovoi kompetentsii $\mathrm{v}$ usloviyakh polikul'turnogo obshchestva: sbornik nauchnykh rabot zaochnoi Mezhdunarodnoi nauchnoprakticheskoi konferentsii (28-29 aprelya 2014 g.). Stavropol': Izd-vo SKFU, 2014. P. 66-72.

5. Danilova, T. A. Vozmozhnosti bilingval'noi podgotovki v formirovanii konkurentosposobnosti budushchego professionala (.Possibilities of bilingual training in shaping the competitiveness of a future professional) // Aktual'nye voprosy razvitiya yazykovoi lichnosti v usloviyakh sovremennogo polikul'turnogo obshchestva (kollektivnaya monografiya) / pod red. Shibkovoi O. S. Stavropol': Izd-vo SKFU, 2016. P. 30-43.

6. Zimnyaya, I.A. Klyuchevye kompetentnosti kak rezul'tativno-tselevaya osnova kompetentnostnogo podkhoda v obrazovanii (Key competences as a result-target basis of the competence approach in education)// Rektor VUZa. 2005. № 6. P. 13-29.

7. Izarenkov, D. I. Bazisnye sostavlyayushchie kommunikativnoi kompetentsii i ikh formirovaniya na prodvinutom etape obucheniya studentov-nefilologov (Basic components of communicative competence and their formation at the advanced stage of training of non-philological students) // Russkii yazyk za rubezhom. -1990 . - №4.

8. Markov, A. P. Obrazovatel'nye tseli i agenty globalizatsii (Educational goals and agents of globalization) // Obrazovanie $\mathrm{v}$ usloviyakh formirovaniya novogo tipa kul'tury: III mezhdunarodnye likhachevskie nauchnye chteniya. SPb.: SPbGUP, 2003. 
9. Mel'nikova M. S. Konstruirovanie mezhdistsiplinarnykh modul'nykh programm v sisteme bilingval'nogo obrazovaniya (Designing interdisciplinary modular programs in the bilingual education system). Tekst: dissertatsiya na soiskanie uchenoi stepeni kandidata pedagogicheskikh nauk: 13.00.01 / Mel'nikova Mariya Sergeevna; [Mesto zashchity: Novgorod. gos. un-t im. Yaroslava Mudrogo]. - Velikii Novgorod, 2008. 247 s.: il. RGB OD, 61 08-13/599.

10. Mitina, L. M. Psikhologiya razvitiya konkurentosposobnoi lichnosti (The psychology of the development of a competitive personality)/L. M. Mitina - M.: MPSI; Voronezh: Izd-vo NPO «MODEK», 2002.

11. Savchenko, I. I., Mylov, I. D. Problemy razvitiya metodologii ponyatiya konkurentosposobnosti (Problems of the development of the methodology of the concept of competitiveness) // Mezhdunarodnyi zhurnal prikladnykh i fundamental'nykh issledovanii. - 2015. - № 11-3. - P. 435-438; URL: http://applied-research. $\mathrm{ru} / \mathrm{en} / \mathrm{article} / \mathrm{view}$ id $=7756$

12. Titova, O. A. Formirovanie konkurentosposobnoi lichnosti v usloviyakh sovremennogo obrazovaniya (The formation of a competitive personality in the conditions of modern education)// Molodoi uchenyi. - 2016. №16.1. - P. 57-60.

13. Fatkhutdinov, R. A. Konkurentosposobnost': ekonomika, strategiya, upravlenie (Competitiveness: Economics, Strategy, Management). M.: INFRA-M, 2000.

14. Khabarova, L. P. Bilingval'noe obrazovanie v vysshei shkole: zarubezhnyi i otechestvennyi opyt (Bilingual education in higher education: foreign and Russian experience) // Izvestiya PGPU im. V. G. Belinskogo. 2011. № 24. P. 846-852.

15. Hesselbein, F., Goldsmith, M., Somerville, A. KhesselbeinF., Goldsmit M., Somervill A. Liderstvo bez granits (Leadership without borders). M., 2001. Nauchnaya biblioteka dissertatsii i avtoreferatov disserCat http:// www.dissercat.com/content/konkurentosposobnost-lichnosti-v-sovremennom-transformiruyushchemsyaobshchestve-sotsialno-f\#ixzz5M227AG3n

16. Khusaenova, A. A. Kompetentnostnyi podkhod $\mathrm{v}$ vysshem obrazovanii (Competence approach in higher education)// Obrazovanie i vospitanie. - 2015. - №4. - P. 23-26. - URL https://moluch.ru/th/4/ archive/13/243/.

17. Shirin, A.G. Didaktiko-metodicheskie aspekty protsessa bilingval'nogo obrazovaniya (Didactic-methodical aspects of the process of bilingual education)// Vestnik novgorodskogo gosudarstvennogo universiteta. 2005. № 31. P. 63-66

18. Shubin, S. V. Motivatsiya ovladeniya inostrannym yazykom v usloviyakh bilingval'nogo obucheniya v vuze (Motivation of mastering a foreign language in conditions of bilingual education in a university): diss. ... kand. ped. nauk. Velikii Novgorod: NovGU imeni Yaroslava Mudrogo, 2000. 148 p.

19. Baker, C. Foundations of Bilingual Education and Bilingualism. Clevedon: Multilingual Matters. 2006. $492 \mathrm{pp}$.

20. Coyle, D. Evaluating the impact of CLIL programmes. Content and Language Integrated Learning. Cambridge English. 2010.

21. Erasmus +. EU program for education, training, sport and youth. URL http://ec.europa.eu/programmes/ easmus-plus/node_en

22. European commission. Multilingualism. [Электронный ресурс]// Content and Language Integrated Learning (CLIL): сайт. URL: http://ec.europa.eu/education/languages/language-teaching/doc236_en.htm

23. Hanvey, R.G. An Attainable Global Perspective. Theory into Practice. Vol. 21, No. 3, Global Education (Summer, 1982), p.p.162-167.

24. Lasagabaster, D. Foreign Language Competence in Content and Language Integrated Courses. The Open Applied Linguistics Journal 1, 31-42. 2008.

25. Meriso-Storm, T. Students' first language skills in bilingual education. Journal of Communications Research3, 85-101. 2001.

26. Ruiz de Zarobe, Y. R. CLIL Implementation: from policy makers to individual initiatives. International Journal of Bilingual Education and Bilingualism, 16:3. 231-243. 2013.

27. Sakharov, A.D. Collected Scientific Works. Ed. D. ter Haar, D.V.Chudnovsky and G.V.Chudnovsky. New York and Basel: Marcel Dekker Inc., 1982.

28. Skutnabb-Kangas, T. Bilingualism or not? The education of minorities. Clevedon, Avon: Multilingual Matters, $1984.378 \mathrm{pp}$. 
29. TEL2L. Teaching subjects through the medium of foreign language // Bilingual Education Programmes in Germany. URL: http://www.unavarra.es/tel21/eng/germany.htm

30. TEL2L. Teaching subjects through the medium of foreign language. Models of bilingual education. URL: http://www.unavarra.es/tel2l/eng/Worldcontext.htm

31. TEL2L. Teaching subjects through the medium of foreign language. The Trilingual Education system in Luxembourg. URL: http://www.unavarra.es/tel21/eng/luxembourg.htm

\section{СВЕДЕНИЯ ОБ АВТОРЕ}

Данилюва Татьяна Александровна, кандидат педагогических наук, доцент, кафедра иностранных языков для гуманитарных и естественнонаучных специальностей, Северо-Кавказский федеральный университет. E-mail: danya1974@yandex.ru

\section{INFORMATION ABOUT AUTHOR}

Danilova Tatiana Aleksandrovna, Candidate of Pedagogic Sciences, Associate Professor, Department of Foreign Languages for the Humanities and Natural Sciences Degrees, North Caucasus Federal University. E-mail: danya1974@yandex.ru 